\title{
Effects of pictorial instruction on paired-associate recall in first-graders
}

\author{
ALICIA K. LOPES and CHARLES L. RICHMAN \\ Wake Forest University, Winston-Salem, North Carolina
}

\begin{abstract}
Twenty male and 20 female first-graders were trained in a paired-associate (PA) learning task to test the hypothesis that instructions to generate interactive mental images of word referents and interactive imagery training administered prior to PA learning facilitate cued recall. Subjects were assigned randomly to one of the following five conditions: (1) separative imagery instructions with prior picture training; (2) interactive imagery instructions with picture training; (3) separative imagery instructions with no prior training; (4) interactive imagery instructions with no prior training; and, (5) a control rote-repetition group. Results of a 2 (pretraining condition) $\times 2$ (imagery instructions) analysis of variance on number of trials to criterion indicated that instructing first-graders to generate interacting images and providing them with interactive pictures prior to PA training facilitated cued recall relative to subjects instructed to generate separate images, subjects not provided with pictures prior to training, and subjects instructed to learn word pairs in a rote manner. It was concluded that imagery instructions facilitate PA recall in first-graders only when such instructions are made highly explicit.
\end{abstract}

Paired-associate (PA) learning is facilitated when adults (Bower, 1970; Bower \& Winzenz, 1970) and preadolescents (Cramer, 1981) are instructed to generate interacting, rather than separate, images. However, instructions to integrate images fail to benefit PA learning for most children below the second grade unless pictures or stimulus objects accompany the imagery instructions (Danner \& Taylor, 1973; Milgram, 1967; Reese, 1967; Rohwer, 1967; Yuille \& Catchpole, 1974). However, Cramer (1981) found that one-third of her first-grade children were able to follow the instructions to integrate images and were superior in recall to those who followed the instructions to generate separate images. Cramer (1981) also reported that all the fifthgrade children who were instructed to integrate images reported doing so, and were superior in PA recall to those who were instructed to separate their images. These findings suggest that the first-graders may be in a transition period in which imagery instructions are not readily understood and/or adhered to. The hypothesis tested in the present study was that first-graders are quite capable of employing imagery strategies but that the instructions to image are not typically understood by these children and are therefore ineffective in the facilitation of learning.

The present study, therefore, assessed the assumption that first-graders' PA learning would be facilitated

This research was supported, in part, by funds from the National Institute of Mental Health (Grant PHS 1 R01 MH36491) and the Wake Forest University Research and Publication Fund to the second author. We are grateful for the help of Kathryn Brown, Karen Blackwell, and Debbie Hough for their contribution to this research. Requests for reprints should be sent to Charles L. Richman, Department of Psychology, Wake Forest University, Winston-Salem, NC 27109. if pictures illustrating the concept of interacting images were employed prior to PA training.

\section{METHOD}

\section{Subjects and Procedure}

Twenty male and 20 female first-grade students with IQ scores ranging from 90 to 110 served as subjects.

The subjects were tested individually on a PA learning task. Two sets of eight noun pairs high in concreteness, imagery, and meaningfulness (Paivio, Yuille, \& Madigan, 1968) served as stimuli. Half the subjects in each group were presented with List 1 , and the other half received List 2 . There was a practice session consisting of eight PA items prior to training. The children who were presented with List 1 (List 2) during practice were subsequently trained on List 2 (List 1) for PA training and testing. The word pairs were presented auditorily on a tape recorder at 5 -sec intervals. The children were instructed to use the strategy taught them during these intervals, and were periodically given a reminder of the pretraining instructions. A single study trial was followed by cued-recall trials. The subjects were given $5 \mathrm{sec}$ to respond to each stimulus. Stimulus-response and stimulus-presentation orders were randomized for each set of study and test trials. Criterion was set at eight out of eight correct responses or 15 trials.

\section{Design}

The experimental design consisted of a $2 \times 2$ factorial, with factors of presence or absence of pretraining pictures and separative or integrative instructions. Eight children were assigned randomly to each group. The subjects in the separative imagery group were instructed to form separate mental pictures ("inthe-head pictures") of the word referents. The children in the integrated image condition were instructed to form a mental picture of the word referent interacting in some way.

Pretraining with pictures was accomplished by presenting the children with three colored pictures depicting two objects separated (separative condition) or two objects interacting (integrative condition). The subjects trained in the no-picture groups were instructed to form either separate or interacting images, but were not provided with pictures during pretraining. 
An additional group of eight children, the control group, were administered standard PA instructions, that is, "Repeat the words over and over again until you hear the next two words."

\section{RESULTS}

A 2 (gender) $\times 2$ (pretraining condition) $\times 2$ (imagery instructions) analysis of variance was performed on the trials-to-cued-recall-criterion scores on the second set of eight PA items. The main effects of gender, pretraining, and imagery were not statistically significant $[\mathrm{Fs}(1,24)=.21,1.91$, and 1.61 , respectively, ps $>.10]$. With the exception of the pretraining $\mathrm{x}$ imagery interaction $[\mathrm{F}(1,24)=10.41, \mathrm{p}<.005]$, none of the interactions were statistically significant $(\mathrm{ps}>.10)$. Table 1 presents the mean trials to criterion for the groups represented in the pretraining $x$ imagery interaction and the rote control group.

The means in Table 1 indicate, and were verified via a Duncan multiple range test, that subjects pretrained with pictures and instructed to generate integrated images reached criterion in fewer trials than did the remaining three experimental groups $(\mathrm{ps}<.05)$. The picture-separate, no picture-separate, and no pictureintegrate groups did not differ in their trials to criterion (ps $>.10$ ). Furthermore, subsequent statistical comparisons showed that the rote control subjects required more trials to reach criterion than the picture-integrate group $(\mathrm{p}<.05)$, but the former did not differ from the remaining three experimental groups $(\mathrm{p}>.10)$. The List 1 versus List 2 trials-to-criterion mean scores were 8.5 and 8.0 , respectively $(\mathrm{p}>.10)$.

\section{DISCUSSION}

Several investigators have shown that first-grade children's cued recall is facilitated when, and only when, interacting pictures or simulus objects are provided during PA training (Danner \& Taylor, 1973; Milgram, 1967; Reese, 1967; Rohwer, 1967; Yuille \& Catchpole, 1974). The results of the present study demonstrated that instructing first-graders to generate interacting images and providing them with interacting pictures prior to PA training facilitates cued recall relative to subjects instructed to generate separate images, subjects not provided with pictures prior to training, and subjects instructed to learn word pairs in a rote manner.

These findings suggest that first-grade children are quite capable of generating interacting images, without the presence

Table 1

Mean Trials to Paired-Associate Learning Criterion as a Function of Imagery Instructions and Pretraining

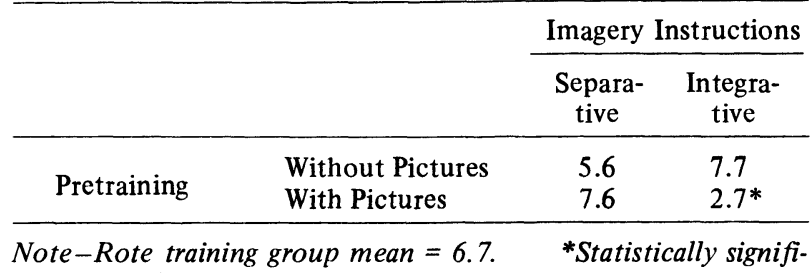

cant from all other groups $(p<.01)$. of pictures or stimuli during training. The failure of most firstgraders to employ effective imaginal strategies (Eoff \& Rohwer, 1972; Wolff \& Levin, 1972) may have been due to the children's inability to comprehend the precise nature of the instructions to image.

An inference derived from previous research suggests that first-grade children are in transition in the spontaneous use of imaginal strategies (see also Yuille \& Cathchpole, 1973). For example, instructing first-graders to generate interacting images is not as effective a procedure in facilitating PA learning as having them generate sentences from word pairs; however, these strategies are equally effective for fourth-graders (Kemler \& Juscyzk, 1975). Furthermore, instructions to image fail to facilitate PA learning in first-grade students (Eoff \& Rohwer, 1972; Wolff \& Levin, 1972) unless instructions are accompanied by pictures during training and testing (Milgram, 1967; Reese, 1967; Rohwer, 1967). However, the facilitation of PA learning via imagery instructions does not require pictures during testing for students beyond the second grade (Bower, 1970; Cramer, 1981; Kemler \& Jusczyk, 1975). On the basis of the present results, we suggest that, in the absence of pictures during training and testing, paired-associate learning in first-graders is facilitated when, and only when, the instructions are made highly explicit, for example, via interacting pictures.

\section{REFERENCES}

Bower, G. H. (1970). Imagery as a relational organizer in associative learning. Journal of Verbal Learning and Verbal Behavior, 9, 529-533.

Bower, G. H., \& Winzenz, D. (1970). Comparison of associative learning strategies. Psychonomic Science, 20, 119-120.

Cramer, P. (1981). Imagery and learning: Item recognition and associative recall. Journal of Educational Psychology, 73, 164-173.

Danner, F. W., \& TAYlor, A. M. (1973). Integrated pictures and relational imagery training in children's learning. Journal of Experimental Child Psychology, 16, 47-54.

EofF, J. E., \& Rohwer, W. D. (1972, April). A developmental study of imagery instructions in noun-pair learning. Paper presented at the meeting of the American Educational Research Association, Chicago.

Kemle R, D. G., \& Jusczyk, P. W. (1975). A developmental study of facilitation by mnemonic instruction. Journal of Experimental Child Psychology, 20, 400-410.

Milgram, N. A. (1967). Verbal context versus visual compound in paired associate learning by children. Journal of Experimental Child Psychology, 5, 597-603.

Paivio, A., Yuille, J. C., \& Madigan, S. A. (1968). Concreteness, imagery, and meaningfulness values for 925 nouns. Journal of Experimental Psychology Monographs, 76(1, Pt. 2).

REESE, H. W. (1967). Imagery in paired-associate learning in children. Journal of Experimental Child Psychology, 2, 290-296.

ROHWER, W. D., JR. (1967). Social class differences in the role of linguistic structures in paired-associate learning: Elaboration and learning proficiency (Basic Research Project No. 5-0606, Contract No. OE 6-10-273). Washington, DC: United States Office of Education.

Wolff, P., \& Levin, J. R. (1972). The role of overt activity in children's imagery production. Child Development, 43, 537-547.

Yuille, J. C., \& CATChPole, M. J. (1973). Associative learning and imagery training in children. Journal of Experimental Child Psychology, 16, 403-412.

Yuille, J. C., \& Catchpole, M. J. (1974). The effects of delay and imagery training on the recall and recognition of object pairs. Journal of Experimental Child Psychology, 17, 474-481.

(Manuscript received for publication May 8, 1984.) 